\title{
Effect of Recycled Concrete Aggregates on Compressive Strength and Water Permeability of Concrete
}

\author{
Tehmina Ayub ${ }^{1}$, Asad-ur-Rehman Khan ${ }^{1}$, Wajeeha Mahmood ${ }^{1}$ \\ ${ }^{1}$ Department of Civil Engineering, NED University of Engineering \& Technology, Pakistan.
}

\begin{abstract}
This paper discusses the effects of recycled concrete aggregates (RCA) on compressive strength and permeability of recycled aggregate concrete (RAC) by using recycled concrete aggregates as a replacement of natural coarse aggregates (NCA). Four replacement percentages were used to study the effect of replacement. Replacement percentages used were $30 \%, 50 \%, 70 \%$ and $100 \%$ with $0 \%$ replacement was used as control. Mix design of 1:1.24:2.6 was used in the study with water to cement ratio of 0.43. Influence of RCA on compressive strength was determined for all the mixes as per ASTM C39 standard. The permeability of all the mixes was determined by measuring absorption, sorptivity and Darcy's coefficient. Results of compressive strength indicated that concrete with $30 \%$ replacement of NCA can be successfully used in structural concrete without compromising too much on strength. Whereas, the replacement of natural aggregates with RCA has a negative impact on the permeability of concrete at all replacement levels. Absorption, sorptivity and permeability of natural aggregate concrete is lower as compared to RAC with $30 \%$ replacement showing the better performance as compared to other replacement ratios.

Keywords: Concrete Aggregates, sorptivity, Compressive Strength, Water Permeability of Concrete
\end{abstract}

\section{INTRODUCTION}

With the preferment of modern concrete technology, the progress of industrialization development based on the reduced cost of resource consumption and environmental destruction has been accelerating across the globe. Several significant test results are available in the literature related to the ordinary concrete made up of recycled concrete aggregates (RCA) with pozzolanic materials $[1,2]$ and without pozzolanic materials [3], as well as in the pervious concrete [4, 5]. Bhikshma and Divya [1] also studied the permeability of RAC using fly ash. For this purpose, the fly ash content was used up to $30 \%$, and overall four (04) concrete grades M20, M25, M30, M35 were prepared while recycled aggregates completely replaced natural aggregates. Compressive strength of RAC for each concrete type was found increasing when the amount of fly ash used was less than or equal to $20 \%$. However, the trend was reversed with the increase in the amount of fly ash beyond $20 \%$ up to $30 \%$. Results of permeability of RAC were expectedly higher than concrete made up of natural aggregates. Still, the addition of fly ash resulted in the overall enhancement of the permeability resistance of RAC. Saini and Goel [2] examined the strength and permeability of ordinary concrete with 50 , and $100 \%$ recycled coarse aggregates by incorporating silica fume as 5 to $10 \%$ replacement of cement by weight. Utilization of $10 \%$ silica fume significantly improved the mechanical properties and durability performance of RAC. Adnan et al. [3] studied the permeability of RAC with NAC by using $0 \%, 25 \%, 50 \%, 75 \%$ and $100 \%$ content of RCA. Mix designs used in the study were cast with water to cement $(\mathrm{w} / \mathrm{c})$ ratio $0.4,0.5$ and 0.6. Water permeability of RAC was the main parameter investigated in the study which was found to be on the higher side for RAC as compared with NAC.

Sriravindrarajah et al. [4] determined the 7 and 28 days compressive strength along with the water permeability under the falling head and void content of the pervious concrete. Reported results showed that the compressive strength and coarse aggregate size are inversely related, and the use of recycled aggregate lowered the 28-day compressive strength as compared to the natural aggregates. However, the water permeability is independent of aggregate type (i.e. natural or recycled) but mainly influenced by the concrete porosity. Ying et al. [5] investigated the 
impact of water reducer, cement content, sand ratio, water and aggregate ratio to the cement. In a way, they studied the various compressive strengths (10 to $20 \mathrm{MPa}$ ) of water-permeable concrete (or pervious concrete) using $9.5 \mathrm{~mm}$ to $16 \mathrm{~mm}$ diameter range of recycled concrete aggregates. The outcome of the study revealed that aggregate size strongly impacted the compressive strength and aggregate size ranging from range of 9.5 to $16 \mathrm{~mm}$ diameter is the best for the water-permeable concrete from compressive strength's point of view. Further, the increasing water-cement $(\mathrm{w} / \mathrm{c})$ ratio increased the water permeability initially, which later on showed declined trend. According to Ying et al. [5], $0.33 \sim 0.40 \mathrm{w} / \mathrm{c}$ ratio is the optimum for permeability.

In this paper, test results of compressive strength and permeability parameters of RAC using $0 \%, 30 \%$, $50 \%, 70 \%$ and $100 \%$ replacement percentages of natural coarse aggregates with recycled coarse aggregates are presented and discussed. In all concrete mixes, 1:1.24:2.6 mix proportion was used. The water-to-cement ratio of 0.43 was used in all mix types. ASTM standard C39 [6] was used to determine the compressive strength. The permeability parameters were measured in terms of absorption, sorptivity and Darcy's coefficient. This study is essential for Pakistani Construction Industry as sustainable construction in Pakistan has not received enough attention in the past.

\section{EXPERIMENTAL METHODOLOGY}

The methodology of this study was divided into four phases: Mix design selection, Material selection, Casting and testing of specimens, and Results analysis. In the first phase of the methodology, mix design was chosen from the mix design already explored by the Chinese Counterpart Professor Jianzhuang Xiao [7]. For the mix design given in Table 1 , the slump was targeted as $100 \pm 10 \mathrm{~mm}$. The mix design and the amount of Superplasticizer used are shown in Table 1.

In the second phase, the materials for NAC and RAC were selected. Cement used for the concrete mix mentioned in Table 1 was ASTM (Type I). The cement content was fixed and the same for every batch. Natural aggregates of two sizes were used in this investigation in the proportions of $40 \%$ and $60 \%$ of the total weight of the coarse aggregates given in Table 1. Aggregates passing through $20 \mathrm{~mm}$ and retained on $15 \mathrm{~mm}$ size sieve were collected and were used as 40 percent of the total weight of coarse aggregates given in Table 1. Aggregates sieved through $15 \mathrm{~mm}$ and retained on $5 \mathrm{~mm}$ size sieve were used as 60 percent of the total value of the weight of the coarse aggregate, and given in Table 1. The saturated surface dry natural aggregates, obtained from the local quarry site, were used.

TABLE 1. Mix design of recycled aggregate concrete

\begin{tabular}{|c|c|c|c|c|c|c|c|c|}
\hline \multirow{2}{*}{$\begin{array}{l}\text { Concrete } \\
\text { mixes }\end{array}$} & \multirow{2}{*}{$\begin{array}{c}\text { Natural } \\
\text { aggregate } \\
\text { replacement }\end{array}$} & \multirow{2}{*}{$\begin{array}{c}\text { w/c } \\
\text { ratio }\end{array}$} & \multicolumn{5}{|c|}{ Quantities $\left(\mathrm{kg} / \mathrm{m}^{3}\right)$} & \multirow{2}{*}{$\begin{array}{c}\text { The percentage } \\
\text { amount of } \\
\text { Superplasticizer }\end{array}$} \\
\hline & & & Cement & $F A$ & $N C A$ & $R C A$ & Water & \\
\hline RCA-0 & $0 \%$ & 0.43 & 454 & 568 & 118 & - & 195 & 1.6 \\
\hline RCA-30 & $30 \%$ & 0.43 & 454 & 536 & 783 & 335 & 195 & 1.5 \\
\hline RCA-50 & $50 \%$ & 0.43 & 454 & 517 & 539 & 539 & 195 & 1.3 \\
\hline RCA-70 & $70 \%$ & 0.43 & 454 & 500 & 313 & 729 & 195 & 1.25 \\
\hline RCA-100 & $100 \%$ & 0.43 & 454 & 475 & - & 991 & 195 & 0 \\
\hline
\end{tabular}

Note: in the following table, terms "FA", "NCA", and "RCA" represents "fine aggregate", "natural coarse aggregate", and "recycled coarse aggregate." 
Recycle concrete aggregate (RCA) were also acquired of similar sizes as NCA from 3 to 4 years by demolishing and crushing some old concrete specimens. After that, recycled coarse aggregates were sieved in a similar way adopted for NCA. After that, the physical properties of RCA were determined, which are given in Table 2 .

For fine aggregates, sand passing through $10 \mathrm{~mm}$ sieve was used. Ordinary tap water was used in mixing the concrete. It was made sure that water should be free from all kinds of impurities including alkalis, acids, salts or any other thing that could alter or affect the properties of the concrete, as per ASTM C1602 [10].

The procedure of concrete mixing was followed from BS 1881-125 [11]. After mixing, the slump test was performed for each concrete mix type following the procedure given in ASTM C143/C143M [12]. After that, specimens for the mechanical properties and permeability tests were cast following the methodology of ASTM C192 / C192M [13]. For each concrete mix type, 6 cylinders (size: $100 \mathrm{~mm}$ (diameter) $\times 200 \mathrm{~mm}$ height) were cast for 7 and 28 days testing.

Similarly, three cubes (size: $100 \mathrm{~mm} \times 100 \mathrm{~mm} \times$ $100 \mathrm{~mm}$ ) were cast from each concrete mix for the permeability test. Once the casting of specimens was completed, all samples were wet cured in a water curing tank after demolding. Results obtained from the conducted experiments are presented in the forthcoming section.

\section{EXPERIMENTAL TESTS, RESULTS AND DISCUSSION}

Results of the experimental investigations carried out during the reporting period are discussed in the following sections.

\section{III.a Compressive Strength Test}

Compressive strength of RAC was determined after 7 and 28 days of curing and subsequent drying of cylinders as per ASTM C39 [7]. The uniaxial compression test was carried out using the Universal Testing Machine (Model No. UH-500KNI). For the uniform loading, sulfur capping was applied over the surface of the cylinders.

TABLE 2. Physical properties of recycled aggregates

\begin{tabular}{lccc}
\hline \multicolumn{1}{c}{ Properties } & NCA & RCA & ASTM Standard \\
\hline Bulk specific gravity (dry) & 2.646 & 2.385 & C127-15 [8] \\
Bulk specific gravity (saturated) & 2.666 & 2.466 & C127-15 [8] \\
Apparent gravity & 2.7 & 2.59 & C29M- 09 [9] \\
Absorption (\%) & 0.78 & 3.25 & C29M- 09 [9] \\
\hline
\end{tabular}




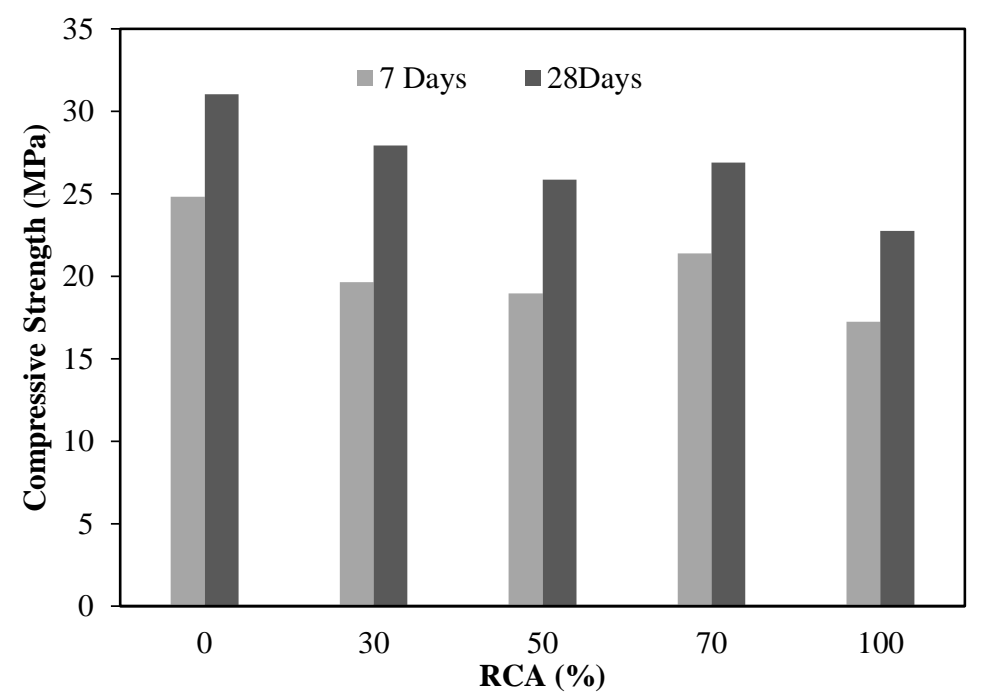

Fig. 1. Effect of RCA percentages on the compressive strength of recycled aggregate concrete

Comparison of compression test results performed at seven (07) and twenty-eight (28) days based on the used RCA percentage is shown in Fig. 1. The reduction in compressive strength can be noticed with the increase in RCA percentage. In general, it was observed that an increase in the percentage of RCA resulted in a decrease in concrete compressive strength, which conforms with the results available in the literature [6]. At $70 \%$ content of RCA (and 30\% NCA), an unusual increase was observed at seven (07) days and twenty-eight (28) days. It suggests the further need for investigation (through retesting or by microstructure examination), which unfortunately could not be performed in the current study. At $70 \%$ replacement, the compressive strengths obtained after seven (07) and twenty-eight (28) days of curing were $21 \mathrm{MPa}$ and $26 \mathrm{MPa}$, respectively.

\section{III.b Water Permeability of Recycled Aggregate Concrete}

Absorption, Sorptivity and Permeability coefficient (Darcy's coefficient) are the parameters to describe the concrete quality in terms of its resistance against hydraulic permeability.

Absorption is a measure of the effective porosity in a concrete sample. In other words, it is representative of the mass increase in the specimen due to water absorption through capillary pores. It is an important parameter to determine the performance of concrete against the effect of environmental loads.
The following relation calculated absorption (\%):

Water Absorption $(\%)=\left[\left(W_{2}-W_{l}\right) / W_{l}\right] \times 100$

In Eq. (1), " $W_{l}$ " is the oven-dry weight of the cubes in grams while " $W_{2}$ " is the weight measured after 1.5 hours of water soaking in grams.

Sorptivity (S) is characterized as the tendency of a spongy material to absorb and diffuse water by the capillarity. During this process, the dynamic force for water penetration into the concrete is capillary suction within the concrete pore system. The testing for Sorptivity is more representative of conventional field conditions. Jiménez and Moreno [14] recommended that gel pores and total pore volume of the capillary in concrete can also be measured using this procedure. Sorption is dependent on both effective porosity and the capillary pressure. Capillary pressure and the pore size are related to each other through Young-Laplace equation, and the gel pores and pore space in the capillary are referred to the effective porosity. Furthermore, the variation in pore size is the cause of different capillary stress, which can be estimated by the average size of pores.

According to ASTM C1585 [15], the cumulative water absorption (per unit area of the inflow surface) increases with the increase in the square root of elapsed time $(t)$. Thus,

$I=S \times t^{1 / 2}$

Therefore, $S=I / t^{1 / 2}$ 
In Eq. (3), " $S$ " is sorptivity in $\mathrm{mm} / \mathrm{min}$, " $t$ " is the elapsed time in minutes, $I=\frac{\Delta W}{A} \times d$ where $\Delta \mathrm{W}$ is the change in weight measured as $W_{2}-W_{l}$, " $\mathrm{A}$ " is the specimen's surface area through which the water is penetrated, and "d" is the density of water. Olorunsogo and Padayachee [16] had made a range, which is shown in Table 3.

TABLE 3. Relationship between sorptivity and durability level [16]

\begin{tabular}{cc}
\hline Sorptivity $\left(\mathbf{m m} / \mathbf{h}^{\mathbf{1} / 2}\right)$ & Durability level \\
\hline$<6.0$ & Excellent \\
\hline $6.0-10.0$ & Good \\
\hline $10.0-15.0$ & Poor \\
\hline$>15.0$ & Very poor \\
\hline
\end{tabular}

The depth of water penetration is another significant parameter to get an idea of water permeability. On the other side, it is likely to estimate the permeability coefficient (Darcy coefficient) in $\mathrm{cm} / \mathrm{sec}$ using the given relationship:

$$
K=\frac{c c \times h}{A \times t \times P}
$$

In Eq. (4), " $c c$ " is the permeated water in $\mathrm{cm}^{3}$, " $\mathrm{h}$ " is the height of cube (in $\mathrm{cm}$ ) and " $t$ " is the time to permeate water (sec), and " $P$ " is the hydrostatic pressure in $\mathrm{cm}$. of the water column.

In order to measure absorption, capability, sorptivity and depth of water penetration, automatic concrete water permeability apparatus was used. For the hydraulic permeability test, each of three cubes of $100 \mathrm{~mm} \times 100 \mathrm{~mm} \times 100 \mathrm{~mm}$ was weighed before placing in the triaxial (or Hassler) cell. Three samples were placed at the same time in three different cells, as per ASTM C642 standard [17], and depth of water penetration was measured as per BS EN 12390-8 [18]. The hydraulic/hydrostatic pressure of 5 bar (100 $\mathrm{mm}$ of water column) is applied for around 72 hours (259200 seconds). After 72 hours, the samples were taken out and weighted again. Immediately after weighing, samples were split into two, and the depth of water penetration was measured on the cracked surface. The infusion of water through the test specimen is collected directly and measured using a graduated cylinder.

Fig. 2 shows the absorption of the concrete mixes concerning time, whereas the sorptivity of five concrete mix types is shown in Fig. 3. In these graphs, it is clear that absorption and sorptivity are increasing with respect to time and replacement percentages. This result is coherent with the one mentioned by Adnan et al. [3] that the absorption and sorptivity of concrete increases with the increase in the percentage of recycled aggregates. It can be associated with RCA, which contains mortar attached to its surface, resulting in increased demand for water in RAC for hydration as compared natural aggregate concrete.

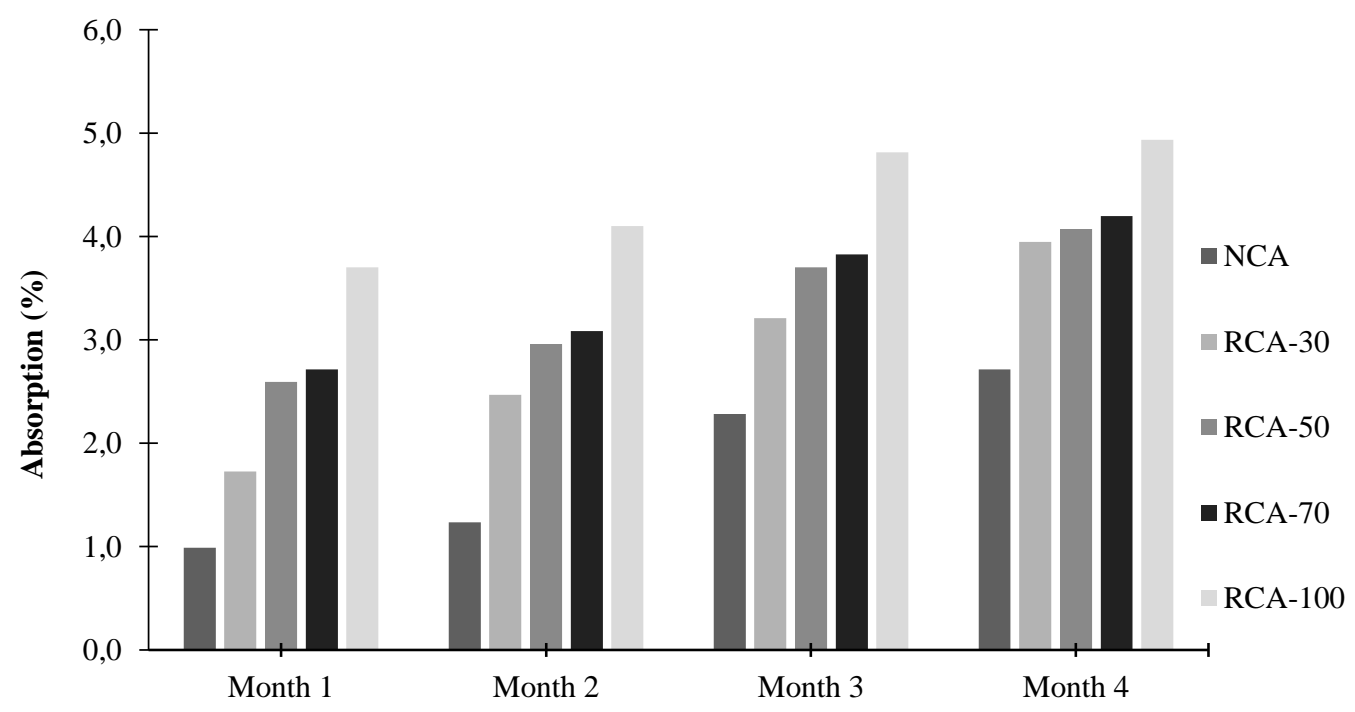

Fig. 2. Absorption of RAC up to 4 months of testing 


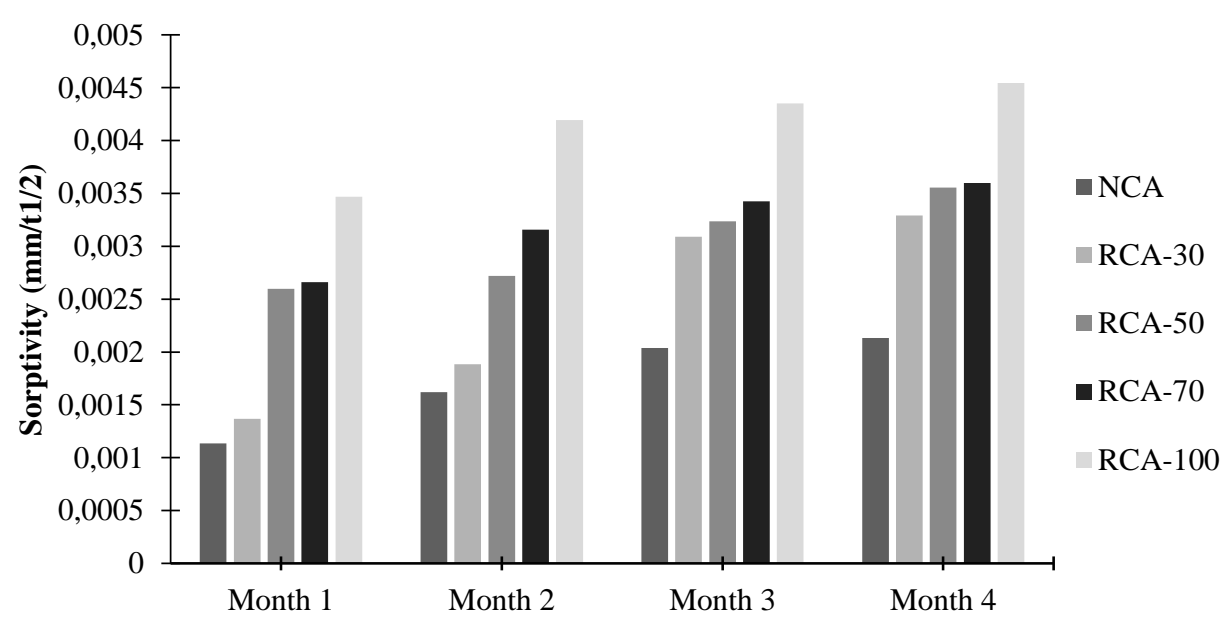

Fig. 3. Sorptivity of recycled aggregate concrete up to 4 months

Fig. 4 describes the permeability coefficient or Darcy's coefficient calculated from 1 to 4 months of testing performed on the concrete mixes. The graph shows a specific trend in which the permeability of recycled aggregate concrete mix is increasing with respect to time. As time increases, the permeability coefficient also increases while on the other hand, permeability also increased with the increasing portion of recycled aggregate in the concrete. The permeability of RCA 100 is highest in all the 4month's test while the NCA is lowest in each month's test. These test results are coherent with the one reported in [1,2]. The reason of this trend can be associated to the porous structure of recycled aggregates due to which RAC exhibit high permeability, absorptivity and sorptivity with respect to time as compared to NAC as shown in Fig. 2 and Fig. 3. In general, RAC is less durable and less resistant to current due to porous structure, and high potential difference values were found as the replacement percentages increases.

\section{CONCLUSIONS}

From the test results assembled during the project, the following conclusions are extracted:

- The result showed that compressive strength with RCA was lower than NCA. The decrease in compressive strength at $100 \%$ RCA content was significant. At the same time, slightly reduced compressive strength was observed at $30 \%$ and $70 \%$ content of RCA. For concrete with $30 \%$ replacement of NCA with RCA, the results were approximately the same. It, therefore, can be concluded that concrete with $30 \%$ replacement of NCA with RCA can be used as structural concrete.

- Results of permeability tests showed that the RCA replacement resulted in increased permeability of concrete. Absorption, sorptivity and permeability of NAC were lower as compared to RAC due to higher number of pores in RAC. This leads to the conclusion that in the production of RAC, treated RCA is preferable as over untreated RCA.

The results discussed here are for four months. The study is currently being extended for a more period to conclude the durability performance of RCA.

\section{ACKNOWLEDGMENTS}

This work is a part of a research project awarded to NED University of Engineering and Technology, Karachi, Pakistan (Project No. PSF/NSFC/Eng-SNED (05)) as a mutual collaboration between National Science Foundation (NSF), China and Pakistan Science Foundation (PSF). 


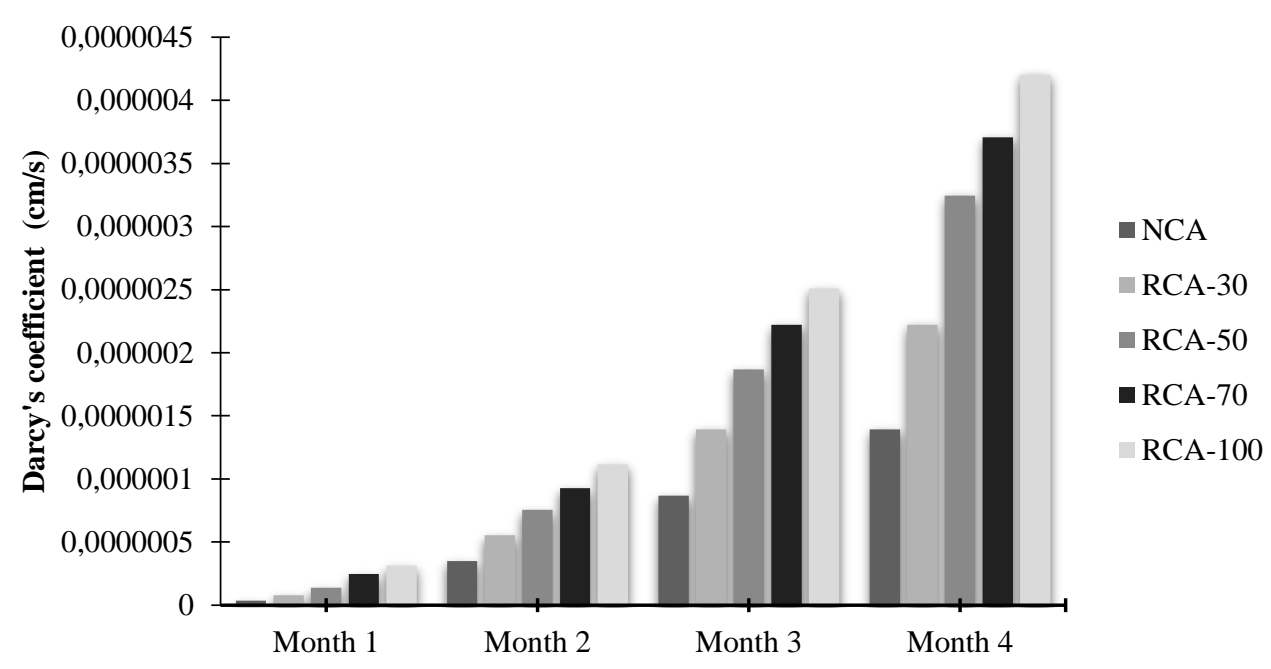

Fig.4, Darcy's coefficient with respect to time

\section{REFERENCES}

1. V. Bhikshma, and K. Divya, "Study on the permeability of the recycled aggregate concrete using fly ash," in 37th Conference on Our World in Concrete. Singapore, 598, 2012.

2. M. Saini and S. Goel, "Strength and permeability of recycled aggregate concrete containing silica fumes," International Journal of Innovative Research in Science, Engineering and Technology (IJIRSET), 2016, vol. 5, pp.1767517682.

3. S.H. Adnan, L.Y. Loon, I.A. Rahman, H.M. Saman and M.W. Soejoso, "Water Permeability of Recycled Aggregate Concrete," In Proceedings of the Technology and Innovation for Sustainable Development Conference (TISD2008), Thailand, 2008, pp.5255.

4. R. Sriravindrarajah, N.D.H. Wang and L.J.W. Ervin, "Mix design for pervious recycled aggregate concrete," International Journal of Concrete Structures and Materials, 6, 2012, pp. 239-246.

5. L. Ying, Y.J. Rong and L.J. Yi. "Study on recycled aggregate water-permeable concrete.]," In Proceedings of the 2011 International Conference on Electric Technology and Civil Engineering (ICETCE), Lushan, China, pp. 6236-6239.

6. ASTM C39 / C39M-20, "Standard Test Method for Compressive Strength of Cylindrical
Concrete Specimens," ASTM International, West Conshohocken, PA, USA, 2020.

7. J. Xiao, J. Li and C. Zhang, "Mechanical properties of recycled aggregate concrete under uniaxial loading," Cement and concrete research, 35, 2005, pp. 1187-1194.

8. ASTM C127-15, "Standard Test Method for Relative Density (Specific Gravity) and Absorption of Coarse Aggregate," ASTM International, West Conshohocken, PA, USA, 2015.

9. ASTM C29 / C29M-17a, "Standard Test Method for Bulk Density ("Unit Weight") and Voids in Aggregate," ASTM International, West Conshohocken, PA, USA, 2017.

10. ASTM C1602 / C1602M-18, Standard Specification for Mixing Water Used in the Production of Hydraulic Cement Concrete, ASTM International, West Conshohocken, PA, 2018.

11. BS 1881-125, "Testing concrete-methods for mixing and sampling fresh concrete in the laboratory," 1986.

12. ASTM C143/C143M-15, "Standard Test Method for Slump of Hydraulic-Cement Concrete," ASTM International, West Conshohocken, PA, USA, 2015.

13. ASTM C192, "Standard Practice for Making and Curing Concrete Test Specimens in the Laboratory," ASTM International, West Conshohocken, PA, USA, 2014.

14. L.F. Jiménez and E.I. Moreno, "Durability indicators in high absorption recycled aggregate concrete," Advances in Materials Science and Engineering, 2015, 2015. 
15. ASTM C1585-13, "Standard Test Method for Measurement of Rate of Absorption of Water by Hydraulic-Cement Concretes," (ASTM International, West Conshohocken, PA, USA, 2013).

16. F. Olorunsogo and N. Padayachee, "Performance of recycled aggregate concrete monitored by durability indexes," Cement and concrete research, vol. 32, 2002, pp. 179-185.

17. ASTM C642-13, "Standard Test Method for Density, Absorption and Voids in Hardened Concrete," (ASTM International, West Conshohocken, PA, USA, 2013).

18. BS 12390-8, "Depth of penetration of water under pressure," (British Standards Institution, UK, 2019), p.12.

\section{Creative Commons Attribution License 4.0 (Attribution 4.0 International, CC BY 4.0)}

This article is published under the terms of the Creative Commons Attribution License 4.0

https://creativecommons.org/licenses/by/4.0/deed.en_US 